NSL 02583

\title{
COMPUTER-ASSISTED ESTIMATES OF LESION SIZES AND SHRINKAGE IN DENERVATED AREAS FROM RECEPTOR AUTORADIOGRAMS USING A DIGITIZING TABLET
}

\author{
HELEN S. PAN, GEORGE W. DAUTH, ANNE B. YOUNG and JOHN B. PENNEY, Jr.*
}

Department of Neurology, University of Michigan, Ann Arbor, MI 48109 (U.S.A.)

(Received September 16th, 1983; Accepted December 7th, 1983)

Key words: lesion - receptors - supersensitivity - shrinkage - striatum - pallidum - substantia nigra - autoradiography

\begin{abstract}
Area measurements taken from receptor autoradiograms were employed to estimate the size of striatal kainate lesions and the amount of shrinkage in deafferented projection areas. There was no significant difference in the size of substantia nigra (SN) on the denervated side as compared to the intact side one week and one month after unilateral striatal lesions. Although there was no change in the size of globus pallidus (GP) on the lesioned side one week after the lesion, there was a $17 \%$ shrinkage one month after the lesion. At 3-4 months after the lesion, the amount of shrinkage was $19 \%$ in $\mathrm{SN}$ and $16 \%$ in GP.
\end{abstract}

For many years, neuroscientists have used in vitro binding techniques to study the ontogeny, localization, pharmacology and binding characteristics of receptors for endogenous and/or exogenous ligands. Studies of binding site numbers and affinities in various brain regions after the placement of lesions - be they electrolytic, undercutting or chemical - have revealed information about the connectivity between cell groups, the possible physiological roles of the receptors and the pathology of certain diseases [3, 4]. A major shortcoming of many studies, which has not been addressed adequately by researchers measuring receptor binding in deafferented structures, is the lack of information on the extent of shrinkage in denervated regions. Loss of afferent input to a region could result in increased density of remaining cell bodies and an overestimation of the amount of increase in binding in these deafferented areas. Homogenate binding techniques by themselves do not allow a quantitative estimate of shrinkage. We report here the use of receptor autoradiograms to measure the size of lesions and various brain regions after shrinkage.

Male Sprague-Dawley rats weighing $150-200 \mathrm{~g}$ received unilateral striatal kainate lesions by a microiontophoretic stereotaxic technique described previously [6]. One week, 1, 3 and 4 months after the lesion, rats were decapitated. Brains were quickly removed, mounted on microtome chucks, and sectioned at $20 \mu \mathrm{m}$ at $-20^{\circ} \mathrm{C}$ on a

* To whom all correspondence should be addressed at: Neuroscience Laboratory Building, 1103 East Huron Street, Ann Arbor, MI 48109, U.S.A. 
Lipshaw cryostat. The brain sections were thaw-mounted onto subbed slides. These sections were subjected to three 5 -min preincubations in $50 \mathrm{mM}$ Tris- $\mathrm{HCl} \mathrm{pH} 7.4$ at $4^{\circ} \mathrm{C}$. Subsequently, they were incubated in $1-15 \mathrm{nM}\left[{ }^{3} \mathrm{H}\right]$ flunitrazepam $(78$ $\mathrm{Ci} / \mathrm{mmol}$, Amersham) for $30 \mathrm{~min}$ at $37^{\circ} \mathrm{C}$, subjected to two 2 -min rinses in cold fresh buffer, dried under a stream of hot air, and exposed to LKB Ultrofilm ${ }^{3} \mathrm{H}$ for 10 days. Ultrofilm ${ }^{3} \mathrm{H}$ was then developed in $\mathrm{D}-19$ for $5 \mathrm{~min}$, fixed, and dried. Autoradiograms were projected with a photographic enlarger onto a digitizing tablet (Summagraphic Bit Pad) connected to a PDP-11/23. The outlines of the striatal lesion, globus pallidus (GP) and substantia nigra (SN) were traced onto the digitizing tablet and the area measurements of the enclosed tracings were calculated by the computer. The program for control of the digitizing tablet and calculation of the areas was written in the $C$ programming language. $A$ listing is available upon request. Area measurements of autoradiograms from sequential brain sections 20 or $40 \mu \mathrm{m}$ apart spanning at least $200 \mu \mathrm{m}$ per structure were done. At the lesion site, the ratio of the lesion area to the entire cross-sectional area of the striatum was calculated to give an estimate of the size of the lesion. To estimate the shrinkage of the denervated areas, the ratio of the cross-sectional area of the structure on the deafferented side to that on the intact side was measured.

Autoradiograms of coronal brain sections from rats 3 months after the lesion at the level of the striatum, GP and SN are shown in Fig. 1. The structures analyzed have clearly demarcated boundaries except that imaginary lines defined by the crossing of the anterior commissure were used as ventral boundaries for the striatum and GP. The exact areas analyzed are outlined in the figure. In the brain sections assayed, the lesion affected $57-100 \%$ of the striatum. The estimated amounts of shrinkage at various time points after the lesion are given in Table I. One week after the lesion, there was no observed shrinkage in GP and SN. One month after the lesion, there was likewise no significant difference in the size of $\mathrm{SN}$ ipsi- and contralateral to the lesion, but there was a $17 \%$ shrinkage in GP. Three to 4 months after the lesion, the shrinkage in SN and GP was $19 \%$ and $16 \%$, respectively.

Lesion size and the amount of denervation shrinkage can also be evaluated volumetrically from autoradiograms. A computer can yield the volumes of lesions and denervated and intact structures by integrating cross-sectional areas of these structures over known distances. The ratio of the volume of the lesion or deafferented structure to that of the intact structure represents the total amount of lesion or shrinkage. Since most lesions are partial, the extent of lesion is best represented volumetrically. However, for evaluating autoradiograms of binding, it may be misleading to normalize binding data with respect to the total amount of shrinkage in a denervated structure. Depending on the somatotopic innervation of a particular area, volumetric estimates of shrinkage after the introduction of incomplete lesions may under- or over-estimate the extent of shrinkage in a particular subregion of the structure. Biochemical data are usually taken from adjacent brain sections over a small region. It is desirable then to correlate shrinkage in a particular region to the 


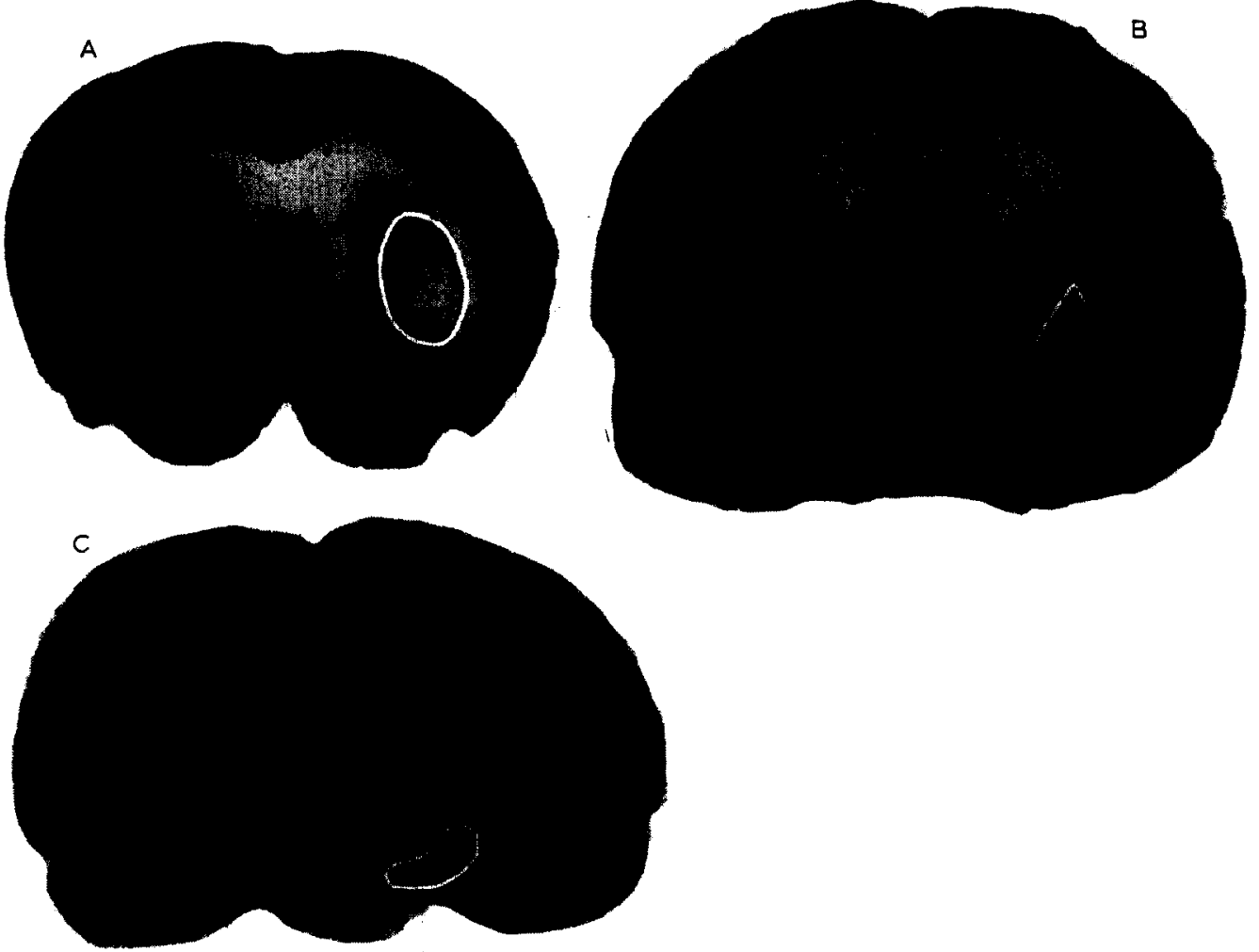

Fig. 1. Autoradiograms of coronal brain sections from rats 3 months after unilateral striatal kainate lesions. A: striatum. B: globus pallidus, GP. C: substantia nigra, SN. The areas analyzed are outlined in white.

\section{TABLE I}

\section{MEASUREMENTS OF CROSS-SECTIONAL AREAS OF SN AND GP AT VARIOUS TIME POINTS} AFTER UNILATERAL STRIATAL KAINATE LESIONS

Area measurements (mean \pm S.E.M.) of SN and GP on the side contralateral to the lesion are expressed in $\mathrm{mm}^{2}$. Area measurements of corresponding structures ipsilateral to the lesion are given as ratios of those on the intact side.

\begin{tabular}{llllll}
\hline Time after lesion & Region & Intact side & $\begin{array}{l}\text { Lesioned side } \\
(\% \text { Intact side) }\end{array}$ & n & $P^{*}$ \\
\hline 1 week & SN & $1.82 \pm 0.03$ & $106 \pm 5$ & 5 & n.s. \\
& GP & $3.39 \pm 0.10$ & $105 \pm 4$ & 5 & n.s. \\
1 month & SN & $2.14 \pm 0.08$ & $92 \pm 8$ & 4 & n.s. \\
& GP & $3.61 \pm 0.08$ & $83 \pm 3$ & 4 & $<0.005$ \\
to 4 months & SN & $1.76 \pm 0.13$ & $81 \pm 5$ & 7 & $<0.025$ \\
& GP & $3.12 \pm 0.19$ & $84 \pm 6$ & 6 & $<0.005$ \\
\hline
\end{tabular}

* One-tailed paired Student's $t$-test.

n.s., not significant. 
biochemical data taken from it. For these reasons, binding data in brain areas should be normalized with respect to the decrease in cross-sectional area of the region undergoing analysis rather than to the entire volume of a structure.

Our data demonstrate the usefulness of autoradiograms in quantitating the amount of denervation shrinkage. Earlier investigators studying receptor binding in deafferented brain regions attempted to deal with the shrinkage phenomenon in various ways. Most researchers use protein levels or wet tissue weight to standardize binding $[1,8]$ but this method does not actually correct for or assess shrinkage. Others have tried gross volume dissection and expressed binding in terms of the entire structures of interest $[2,7]$. We have studied the binding of additional ligands not coupled to the receptor under investigation as a means of defining specific and non-specific receptor changes [6]. While these methods allow an estimate of some aspects of the changes which occur after denervation, they do not directly quantitate the amount of shrinkage. Anatomists have made use of volumetric measurements of structures for many years but their techniques are rarely used by pharmacologists [5]. We have found the anatomical methods useful. With computer-assisted analysis, cross-sectional areas (and volumes) can easily be estimated from receptor autoradiograms which give clearly outlined images of various structures. Lesion sizes and the amount of shrinkage due to denervation can then be evaluated. We have also used the technique with Nissl-stained sections and deoxyglucose autoradiograms. However, the receptor autoradiograms often give the best definition of structure under the enlarger. With information on denervation shrinkage neuroscientists can make more realistic assessments of binding or metabolic changes in deafferented areas of lesioned animals.

This work was supported by NINCDS Grant NS 15655-04, PHS Grants NS00420 and NS00464, NSF Grant BNS-81 18765, United Cerebral Palsy Foundation Grants R-305-82 and R-291-81 and a University of Michigan Minority Fellowship to H.S.P.

1 Biggio, G., Corda, M.G., Lamberti, C. and Gessa, G.L., Changes in benzodiazepine receptors following GABAergic denervation of substantia nigra, Europ. J. Pharmacol., 58 (1979) 215-216.

2 Campochiaro, P., Schwarcz, R. and Coyle, J.T., GABA receptor binding in rat striatum: localization and effects of denervation, Brain Res., 136 (1977) 501-511.

3 Coyle, J.T. and Schwarcz, R., Lesion of striatal neurons with kainic acid provides a model for Huntington's chorea, Nature (Lond.), 263 (1976) 244-246.

4 Creese, I., Burt, D.R. and Snyder, S.H., Dopamine receptor binding enhancement accompanies lesion-induced behavioral supersensitivity, Science, 197 (1977) 596-598.

5 Lehman, M.N., Powers, J.B. and Winans, S.S., Stria terminalis lesions alter the temporal pattern of copulatory behavior in the male golden hamster, Behav. Brain Res., 8 (1983) 109-128.

6 Pan, H.S., Frey, K.A., Young, A.B. and Penney, J.B., Jr., Changes in $\left({ }^{3} \mathrm{H}\right)$ muscimol binding in substantia nigra, entopeduncular nucleus, globus pallidus, and thalamus after striatal lesions as demonstrated by quantitative receptor autoradiography, J. Neurosci., 3 (1983) 1189-1198.

7 Shibuya, H., Gale, K. and Pert, C.B., Supersensitivity to GABA's effect on benzodiazepine receptors develops after striatonigral lesions, Europ. J. Pharmacol., 62 (1980) 243-244.

8 Waddington, J.L. and Cross, A.J., Denervation supersensitivity in the striatonigral GABA pathway, Nature (Lond.), 276 (1978) 618-620. 